\title{
VENA CAVAL INFUSIONS
}

\author{
J. K. Ross, M.B., B.S., F.R.C.S. \\ Department of Surgical Studies, The Middlesex Hospital, London. W.I
}

\section{General Principles}

Intravenous fluid administration direct into the venae cavae is a useful refinement of more orthodox methods involving the use of peripheral veins and is now a well-tried procedure which has been shown to be both safe and reliable.

The underlying principle on which the success of the technique depends is that of instant dilution of the infused fluid as it enters the vena cava. This ensures minimal intimal reaction at the site of delivery of the fluid and enables solutions of high concentration to be given which, if delivered into a peripheral vein, would cause a brisk chemical inflammatory response and rapid thrombosis of the vein.

This same underlying principle, as might be expected, facilitates prolonged administration of standard strength solutions and, in fact, vena caval infusions can be maintained for long periods with no ill effects, a fact appreciated equally by the patient and the house surgeon, who are both spared the consequences of repeated thrombosis of recipient superficial veins.

Using this technique, the patient's activity is scarcely restricted and, beyond the supervision needed for any intravenous infusion, it in no way increases the nursing problems and often makes them easier.

It is possible, using suitable veins of entry, to introduce a polythene cannula into the superior or inferior vena cava. In our experience the superior is preferable to the inferior vena caval route, as the incidence of complications in the former is appreciably less.

\section{Indications}

Vena caval infusions are of great value under any circumstances when intravenous fluids must be given for a long time and may be used with advantage in complicated cases requiring intensive or prolonged preparation for operation, possibly blood transfusion, and intravenous fluids after operation. In this context vena caval infusions have been found useful in the accurate replacement of sustained fluid and electrolyte loss and in the management of patients who, for varied reasons, can have no fluids or other nourishment by mouth for long periods of time.

Vena caval infusions enable strong dextrose solutions to be given, if necessary at a very slow rate, and thus represent a valuable, if not the only, method for giving hypertonic dextrose in the treatment of anuria.

A further application for this technique is found in those patients whose superficial veins have been used up by previous infusions.

\section{Technique}

All vena caval infusions should be set up in the operating theatre, using full aseptic technique. Local anaesthesia is used unless it is decided to start the infusion immediately before or after operation, when it can conveniently be done under general anaesthesia.

The first step is to prepare the polythene cannula, which is sterilized by boiling. All coils should be removed from the tubing by stretching it while it is still warm. The tubing used is $2.5-\mathrm{mm}$. in diameter and of $1.5-\mathrm{mm}$. bore, and this is connected to a standard infusion apparatus by a pentothal mixer, which fits the tubing exactly, giving a watertight and airtight junction. The end of the tubing to be introduced into the vein is cut transversely and its edges rounded by rubbing it rapidly to and fro on one of the sterile towels.

\section{Superior Vena Caval Infusion}

The vein of entry used in this instance is the basilic, the cephalic vein being less satisfactory owing to the angle at which it joins the axillary vein. The basilic vein is exposed before it pierces the deep fascia by a short transverse skin incision $I_{2} \frac{1}{2}$ to 2 in. above and anterior to the medial epicondyle of the humerus, and proof of its identity is afforded by the medial cutaneous nerve of the forearm, which is nearly always found closely related to the vein and which must be dissected free.

Having exposed the vein, the length of tubing to be inserted may be estimated by measuring the distance from the incision to the mid point of the clavicle and from there to the angle of Louis; the 


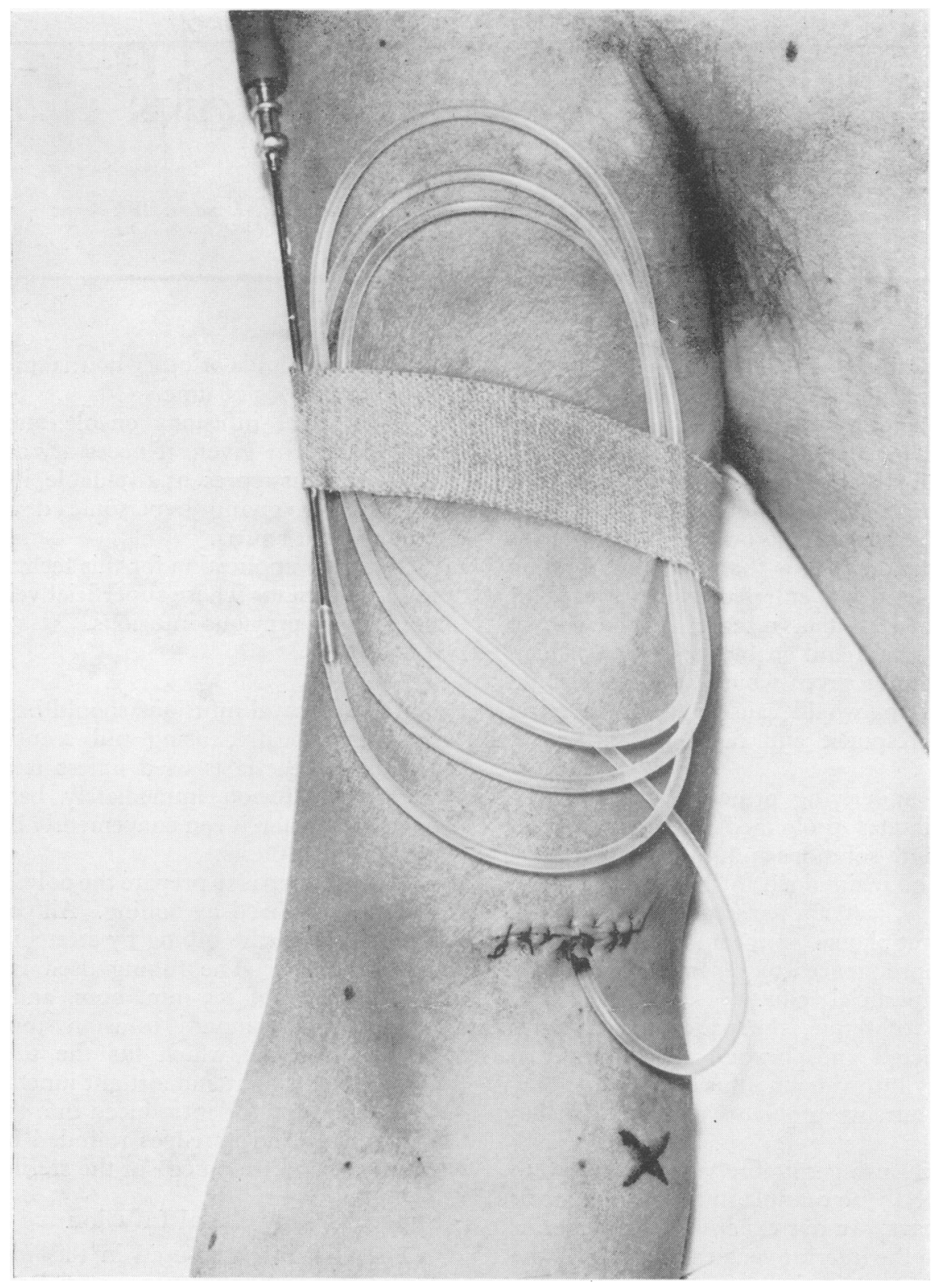

FIG. I.-The photograph shows the pentothal mixer and its junction above with the infusion tubing and below with the polythene cannula. The cross marks the tip of the medial epicondyle of the humerus. The black silk marker on the polythene just below the incision indicates that the full estimated length of tubing has been introduced.

length of tubing used is usually between 14 in. and 16 in. ( 36.5 to $41.5 \mathrm{~cm}$.). Having decided the length of tubing to be used, it is marked off at the appropriate point. The vein is then ligated distally, incised and the cannula inserted with the infusion running slowly.

Once the full length of polythene has been entered it may be possible to see a variation in drip rate with the phases of respiration, indicating that $\omega$ the tip of the cannula is in a major vessel subject to changes in intrathoracic pressure. It may, how- ever, prove impossible to introduce the last few inches of polythene, although this difficulty can sometimes be overcome by more fully abducting ${ }^{\circ}$ 
the arm and slightly flexing the shoulder. If there is a persistent hold-up, which when met always stops the drip, it has been found quite satisfactory to insert the tubing as far as possible compatible with efficient running of the infusion and leave it there, as the fluids are still being introduced into a major vessel and the principle of instant dilution still applies.

When the tubing is in position it is fixed by tying a ligature round both vein and cannula, the skin edges are approximated on either side of the tubing and any extra polythene and the pentothal mixer are fixed to the fore or upper arm by adhesive plaster (Fig. I).

It should be mentioned that on two occasions there has been clear evidence that the polythene tubing has turned upwards, entering the internal jugular vein instead of the superior vena cava. In neither instance were there any resultant ill effects, but if this state of affairs is recognized the tubing should be withdrawn.

\section{Inferior Vena Caval Infusion}

The technique for this route is identical, the vein of entry used in this instance being the long saphenous, which is exposed a short distance below the sapheno-femoral junction.

\section{Addition of Heparin to the Fluids}

As an added safeguard in the prevention of thrombosis at the site of delivery of the fluids into the venae cavae, it is wise to add heparin to the fluids in a dosage of one unit per milliletre (i.e. 500 units of heparin to each standard half-litre bottle). The heparin in this dosage has a purely local anticoagulant effect around the tip of the cannula; this appears true regardless of the volume of fluid given.

\section{Fluids Used}

All fluids in common use for intravenous therapy can be given by the vena caval route. This includes potassium and hypertonic dextrose solutions, which have a known tendency to cause an inflammatory response in superficial veins.

The rate at which the fluids are given can be varied very considerably, both rapid and very slow drip rates being possible.

Antibiotics, vitamin preparations and anaesthetic agents have also all been given via established vena caval infusions, but in regard to the latter some drugs used in anaesthesia (e.g. prostigmine) are better given diluted or in the ordinary way by a peripheral vein.

\section{Results}

Vena caval infusions have been used in the treatment of over 50 patients under our care, of which careful records have been kept in 36 .

In 27 cases the polythene cannula was inserted into the superior vena cava and in nine the inferior vena cava was used.

In all instances when such an infusion has been used a careful watch has been kept for any signs of inflammatory reaction along the course of the vein carrying the polythene tubing and also for any signs of swelling of the limb. If any such signs were found, the tubing was immediately withdrawn. In three of the nine cases in which the inferior vena cava was used there was clinical evidence of femoral vein thrombosis, indicated by swelling of the leg, after the infusions had been running for four, six and eight and a half days respectively. There were no serious consequences and the swelling rapidly subsided on each occasion following the withdrawal of the tubing. As a result of the relatively high incidence of complications met with in this small number of inferior vena caval infusions, the route was abandoned in favour of the superior vena caval method and this accounts for the much larger number of the latter type in the series as a whole.

Of the 27 patients receiving superior vena caval infusions, swelling of the arm developed in three; in two of these the swelling was transitory, subsiding rapidly after stopping the infusions which had run for four and 12 days respectively. The third case had more definite evidence of axillary vein thrombosis after eight days, but again there were no serious sequelae and there was no residual oedema of the arm.

Vena caval infusions have been maintained for from four to 22 days, the average length of time being eight days, and 40 or 501 . of fluid have been given on several occasions without difficulty, the average volume given in the series being 26.51 .

\section{Illustrative Case History}

Mrs. M.W., aged 32. Presenting with recurrent diarrhoea, fatigue and abdominal pain, this patient was found to have Crohn's disease affecting the terminal ileum, for which a right hemicolectomy was performed in November 1956.

She made a good recovery and remained well until March 1957, when diarrhoea of some severity recurred and she was readmitted with very obvious signs of fluid and electrolyte depletion. At that time she was losing between 2 and 31 . of fluid daily from her bowel. She was anaemic and was passing fluid motions containing unaltered bile.

In order to prepare her. for a second operation, water and electrolyte replacement and blood transfusion were needed, and a superior vena caval infusion was therefore set up. This enabled accurate day-to-day replacement of her observed 
abnormal losses, the making good of her established deficit, blood transfusion and ultimately the giving of her post-operative fluid requirements.

At her second operation recurrence of the disease was found in the terminal ileum and the sigmoid colon was also severely affected. A terminal ileostomy was therefore established, which further increased the need for intravenous fluid replacement.

This infusion was maintained for a total of 17 days and transmitted a total of 501 . of fluid, including blood. There were no complications and the patient was intensely grateful for her vena caval infusion, having had the experience of a conventional superficial vein infusion at the time of her first operation.

\section{Summary}

I. The technique of introducing intravenous fluids direct into the venae cavae by means of a polythene cannula is described.

2. The indications for using this technique and its advantages are discussed.

3. The results are given of a series of cases in which this method has been used.

\section{CARCINOMA OF THE BRONCHUS}

\section{(Postgraduate Medical Journal)}

Price 3s. 9d. post free

\section{INTRODUCTORY}

Maurice Davidson, D.M., F.R.C.P.

THE INCIDENCE AND AETIOLOGY OF PRIMARY CARCINOMA OF THE LUNG

C. E. Drew, M.V.O., F.R.C.S.

\section{MEDICAL ASPECTS}

J. Anderson, M.D., F.R.C.P.

RADIOLOGICAL ASPECTS

G. Simon, M.D., D.M.R.E., F.F.R.
UNUSUAL MANIFESTATIONS

J. Smart, M.D., F.R.C.P.

CYTOLOGICAL EXAMINATION OF THE SPUTUM AND PLEURAL EFFUSION

J. L. Pinniger, D.M., M.R.C.P.

THE SCOPE OF RADIOTHERAPY

Gwen Hilton, D.M.R.E., F.F.R.

SURGERY OF CARCINOMA OF THE BRONCHUS

L. L. Bromley, M.Chir., F.R.C.S.

Published by

THE FELLOWSHIP OF POSTGRADUATE MEDICINE

60, Portland Place, London, W.1

Continued from page 61 I-Paralytic Ileus: L. P. Le Quesne, D.M., F.R.C.S.

\section{BIBLIOGRAPHY}

BISGARD, J. D., and JOHNSON, E. K. (1939), Ann. Surg., IIO, 802.

DAVIS, H. H., and HANSEN, T. M. (1945), Surgery, 17, 492.

DEVINE, J. (1946), Brit. F. Surg., 34, 158.

JACQUES, J. E. (1951), Lancet, ii, 861.

LANS, H. S., STEIN, I. F., and MEYER, K. A. (1952), Surg. Gynec. Obstet., 95, 321.

LE QUESNE, L. P. (1957), ' Fluid Balance in Surgical Practice,' and ed., Lloyd-Luke (Medical Books) Ltd., London.

MADDOCK, W. G., BELL, J. L., and TREMAINE, M. J. (1949), Ann. Surg., 130, 512.

MAGNUSSON, W. (1931), Acta radiol., 12, 552.

MARRIOTT, H. L. (1947), Brit. med. Y., i, 245, 285, 328.

MECRAY, P. M., BARDEN, R. P., and RAVDIN, I. S. (1937), Surgery, i, 53.
MORRIS, C. R., IVY, A. C., and MADDOCK, W. G. (1947), Arch. Surg. (Chicago), 55, IOI.

MCIVER, M. A., BENEDICT, E. B., and CLINE, J. W. (1926), Ibid., $13,588$.

PAINE, J. R., CARLSON, H. A., and WANGENSTEEN, O. H. N (1933), Ұ. Amer. med. Ass., 100, 1910.

PERAZZO, G. (1937), Arch. ital. Chir., 47, 163. RANDALL, H. T., HABIF, D. V., LOCKWOOD, J. S., and $\underset{\omega}{\mathrm{N}}$

STREETEN, D. H. P., and VAUGHAN WILLIAMS, E. M. (1952), F. Physiol. (L̈ond.), 118, 149.

STREETEN, D. H. P., and WARD-MCQUAID, J. N. (1952), Brit. med. F., 2, 587 .

WAKIM, K. G., and MANN, F. C. (1943), Gastroenterol. 1, 513. YOUMANS, W. B., MEEK, W. J., and HENIN, R. C. (1938), Amer. F. Physiol., 124, 270. 